\title{
PARTICLE SWARM OPTIMIZATION OF SOLUTION GAS OIL RATIO
}

\author{
${ }^{* 1}$ Okotie, S. and ${ }^{2}$ Fasanya, A. E.
}

\author{
*l Department of Petroleum Engineering, Federal University of Petroleum Resources (FUPRE), Effurun, Delta State, Nigeria \\ *Phone: +2348032608026*Email: okotie.sylvester@gmail.com \\ ${ }^{2}$ Department of Petroleum Engineering, Federal University of Petroleum Resources (FUPRE), Effurun, Delta State, Nigeria \\ Email: engineerberyl@gmail.com
}

\begin{abstract}
Reservoir fluid properties are very important in reservoir engineering computations such as material balance calculation, well test analysis, reserves estimate and numerical reservoir simulations. Ideally, these properties should be obtained from laboratory pressurevolume-temperature (PVT) analysis. Quite often, however, these measurements are either not available, or very costly to obtain. In such cases, empirically derived correlations are used to estimate the needed properties, all computation therefore, will depend on the accuracy of the correlations used for estimating the fluid properties. Hence in this study, Standing's correlation for estimating the solution gasoil ratio was optimized using a particle swarm optimization (PSO) algorithm to minimize the error associated in estimating solution gas-oil ratio from correlation at various depletion pressure. The optimized correlation was taken as a function of bubble point pressure, API gravity, gas gravity and reservoir temperature. PVT data from differential liberation test was used to validate this study's correlation and the result obtained shows that the optimized correlation for this study matches closely with the experimental values, also the newly optimized correlation was validated with other models and the results gave the least average relative error of 3.34 and a correlation coefficient of 0.998 after 216 th successive iterations by the particle swarm optimization algorithm.
\end{abstract}

Keywords: analysis, differential liberation test, gas-oil ratio, PSO, PVT, correlations, reservoir fluid sampling

LICENSE: This work by Open Journals Nigeria is licensed and published under the Creative Commons Attribution License 4.0 International License, which permits unrestricted use, distribution, and reproduction in any medium, provided this article is duly cited.

COPYRIGHT: The Author(s) completely retain the copyright of this published article.

OPEN ACCESS: The Author(s) approves that this article remains permanently online in the open access (OA) mode.

QA: This Article is published in line with "COPE (Committee on Publication Ethics) and PIE (Publication Integrity \& Ethics)". 


\section{INTRODUCTION}

Pressure-volume-temperature (PVT) analysis is the study of the behavior of vapor and liquid in petroleum reservoirs in terms of phase behavior and composition. PVT properties are used to estimate reserves, evaluate the performance of oil and gas reservoirs, design production facilities and production operations. Also, to estimate stock tank gas production rate, cumulative gas-oil ratio, stock tank gas-oil ratio is a key input parameter (Hillary and Okotie, 2016).

Determination of PVT properties among other data, for estimation of the stock oil initial in place and the evaluation of the future performance of hydrocarbon reservoir, is usually associated with uncertainties and as such, it is vital to properly characterize these properties which are key input data for most oil and gas calculations. According to Ikiensikimama and Egbe (2006), at the earlier stages of a well, it can be difficult or economically impractical to obtain reliable measurements of PVT data. In a scenario where the fluid samples are available, they can be subjected to PVT analysis to determine their properties, but samples are often suspected and PVT analysis usually applies only at reservoir temperature. In addition, Ikiensikimama (2008) has it that the reserves estimation and the design of the best depletion strategies are only feasible when a realistic and precise values of reservoir fluid properties are available.

As stated by Okotie et al. (2017), to estimate the PVT properties of a reservoir fluid, the fluid is usually sampled and taken to the laboratory for experimental analysis such as saturation pressure (Dew point) at reservoir temperature, constant composition expansion test for black oil and compositional reservoir fluid to determine properties such as relative volume, vapor z-factor and liquid drop out. Differential Liberation/Vaporization test for black oil only to determine vapour $\mathrm{Z}$ factor, liquid density, gas-oil ratio, relative volume (formation volume factor), gas gravity, liquid viscosity, vapor viscosity. constant volume depletion test for compositional reservoir fluid only to determine the retrograde liquid drop out, cumulative fluid produced, vapor z factor, specific gravity of produced fluid plus, mole weight of produced fluid plus, final weight of produced fluid plus, produced vapor composition and finally, separator test for black oil and compositional reservoir fluid to estimate the gas-oil ratio and stock tank formation volume factor.

Carrying out this study in the laboratory is usually expensive and time-consuming, thus, Engineers in the field resorted to using existing correlation to estimate these properties. The results from these existing correlations are approximations of the field data which yield a considerable amount of error, in order to minimize error associated in estimating the solution gas-oil ratio from experimental, an optimization algorithm is required. Thus, this study is aimed at minimizing the error between the experimented results and the result from existing correlations for accurate estimation of solution gas-oil ratio from correlations

\section{EXISTING PVT CORRELATIONS}

Standing (1947) correlation for gas-oil ratio (GOR) is given by equation (1): 


$$
\begin{aligned}
& R_{s}=\gamma_{g}\left[\left(\frac{p}{18.2}+1.4\right) 10^{x}\right]^{1.2048} \\
& X=0.0125 A P I-0.00091(T-460)
\end{aligned}
$$

Oloruntoba and Onyekonwu GOR equation is given by equation (3):

$$
R_{s}=10^{-0.59255} \gamma_{g}^{2.65582} P^{1.40129} A P I^{0.82132} T^{-0.42583}
$$

Glaso (1980) proposed a correlation for estimating the gas solubility as a function of the API gravity, pressure, temperature, and gas specific gravity given by equations (4-5):

$$
\begin{gathered}
R_{s}=\gamma_{g}\left[\left(\frac{A P I^{0.989}}{(T-460)^{0.172}}\right) 10^{x}\right]^{1.2255} \\
X=2.8869-(14.1811-3.3053 \log P)^{0.5}
\end{gathered}
$$

Al- Marhoun (1985) developed a correlation for estimating the solution gas oil ratio for Middle East crude oil. These correlations were based on a database of 69 bottom hole fluid samples and expressed as a function of reservoir temperature, gas gravity and oil gravity given by equation 6 :

$$
R_{s}=\left(\frac{p \gamma_{g}{ }^{1.87784}}{0.00538088 \gamma_{o}{ }^{3.1437}(T+459.67)^{1.32657}}\right)^{\frac{1}{0.715082}}
$$

Petrosky and Farshad (1993) used a nonlinear multiple regression software to develop a gas solubility correlation. The authors constructed a PVT database from 81 laboratory analyses from the Gulf of Mexico crude oil system. Petrosky and Farshad proposed the following equations (7-8):

$$
\begin{aligned}
& R_{s}=\left[\left(\frac{p}{112.727}+12.340\right) \gamma_{g}^{0.8439} 10^{x}\right]^{1.73184} \\
& X=7.916\left(10^{-4}\right)(A P I)^{1.5410}-4.561\left(10^{-5}\right)(T-460)^{1.3911}
\end{aligned}
$$

Kartoatmodjo and Schmidt (1994) developed a new set of empirical correlation based on a large collection of data developed from all over the world. Their equations (9-10) are given by

$$
\begin{array}{cc}
R_{s}=0.05958 \gamma_{g}^{0.7972} p^{1.0014} 10^{13.1405 \gamma_{A P I}(T+459.67)} & (A P I \leq 30 \\
R_{s}=0.03150 \gamma_{g}^{0.7587} p^{1.0937} 10^{11.2895 \gamma_{A P I}(T+459.67)} & (A P I>30)
\end{array}
$$




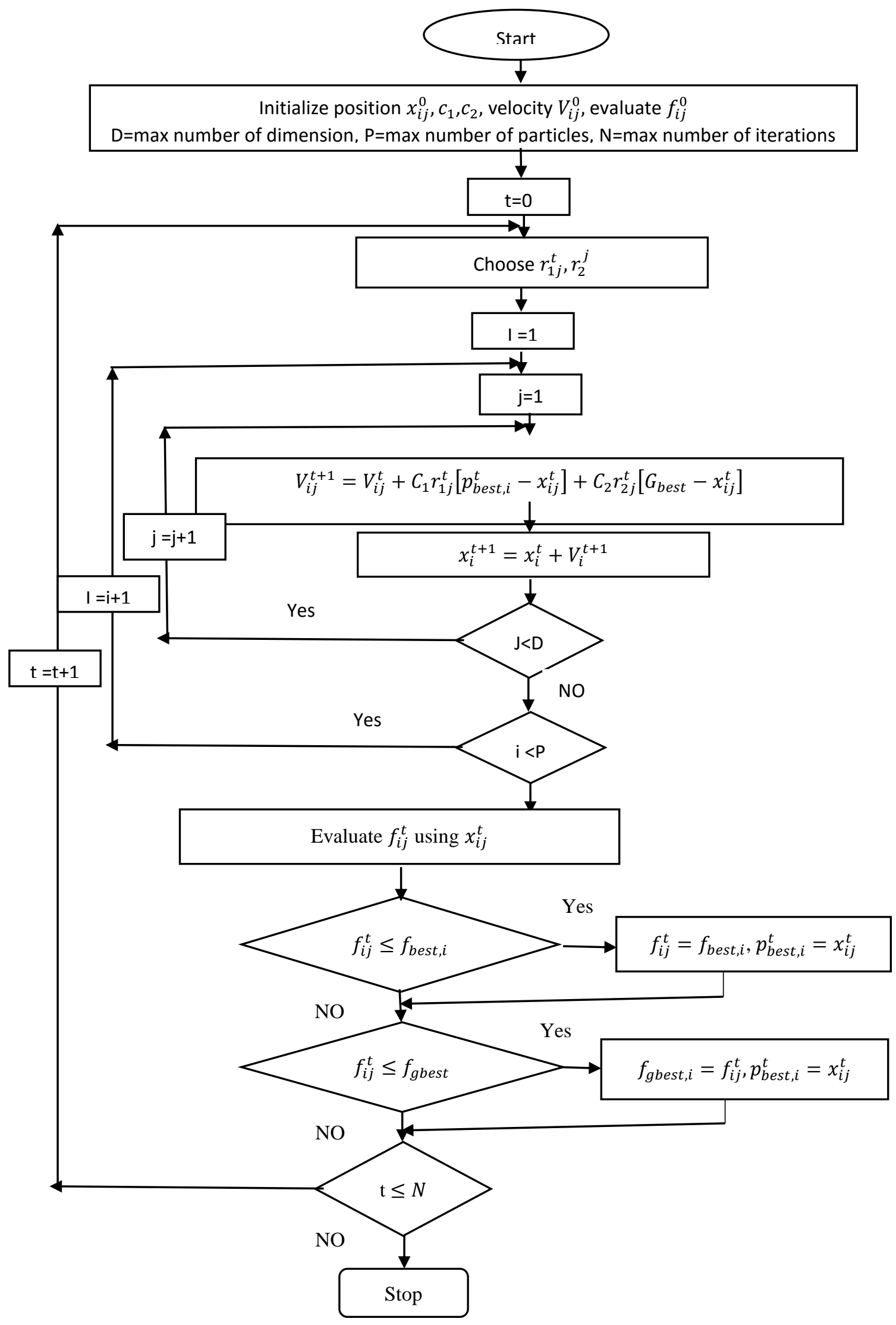

Figure 1: workflow algorithm for the PSO (gbest PSO)

(Source: Satyobroto et al. (2001)) 


\section{THEORECTICAL CONCEPT OF THE PSO ALGORITHM}

Step 1: Choose the number of particles

Step 2: Initialize the initial positions of the particles

Step 3: Evaluate the objective function at the initial positions

Step 4: Set the iteration number as $\mathrm{t}=\mathrm{i}+1$

Step 5: Find the personal best for each particle

Step 6: Find the global best

Step 7: find the velocities of the particles

Step 8: Find the new values of the particles position

Step 9: Find the objective function values of step 6

Step 10: Stopping criterion:

If the terminal rule is satisfied, go to step 4, otherwise stop the iteration and output the results.

\section{INPUT DATA}

Table 1: Differential liberation test data

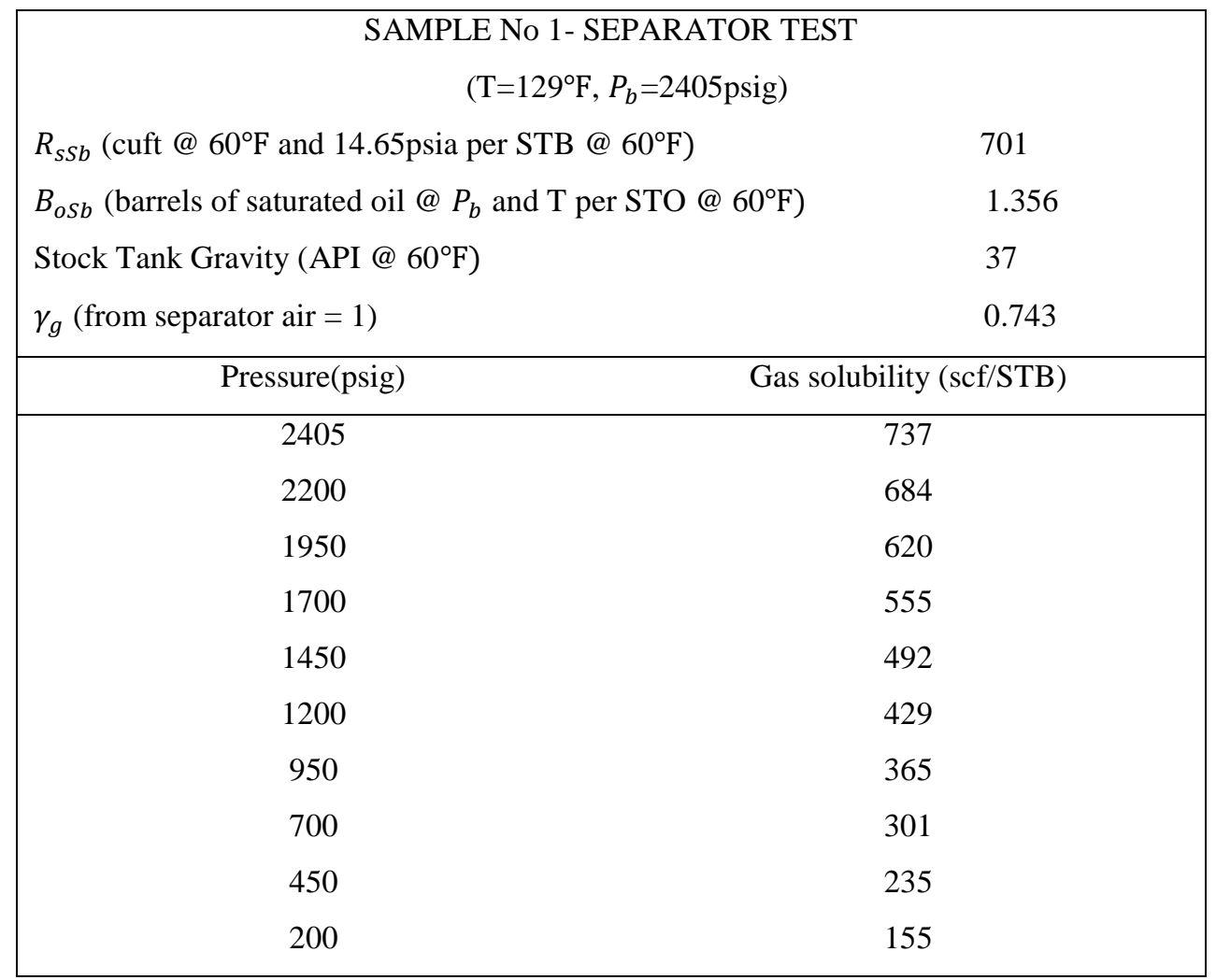




\section{RESULTS}

\section{ESTIMATED RESULT FROM EXISTING CORRELATIONS}

Table 2: Result of gas solubility (scf/stb) from existing correlations

\begin{tabular}{ccccc}
\hline Pressure(psig) & Experimental & Glaso & Standing & Petrosky and Fashad \\
\hline 2405 & 737 & 665 & 703 & 685 \\
2200 & 684 & 500 & 735 & 508 \\
1950 & 620 & 425 & 658 & 467 \\
1700 & 555 & 388 & 575 & 398 \\
1450 & 492 & 319 & 493 & 342 \\
1200 & 429 & 285 & 309 & 297 \\
950 & 365 & 205 & 242 & 255 \\
700 & 301 & 165 & 185 & 200 \\
450 & 235 & 100 & 100 & 170 \\
200 & 155 & 55 & 45 & 125 \\
\hline
\end{tabular}

The results are plotted in Figure 2 to show the disparity in value of the correlations from the experimented value.

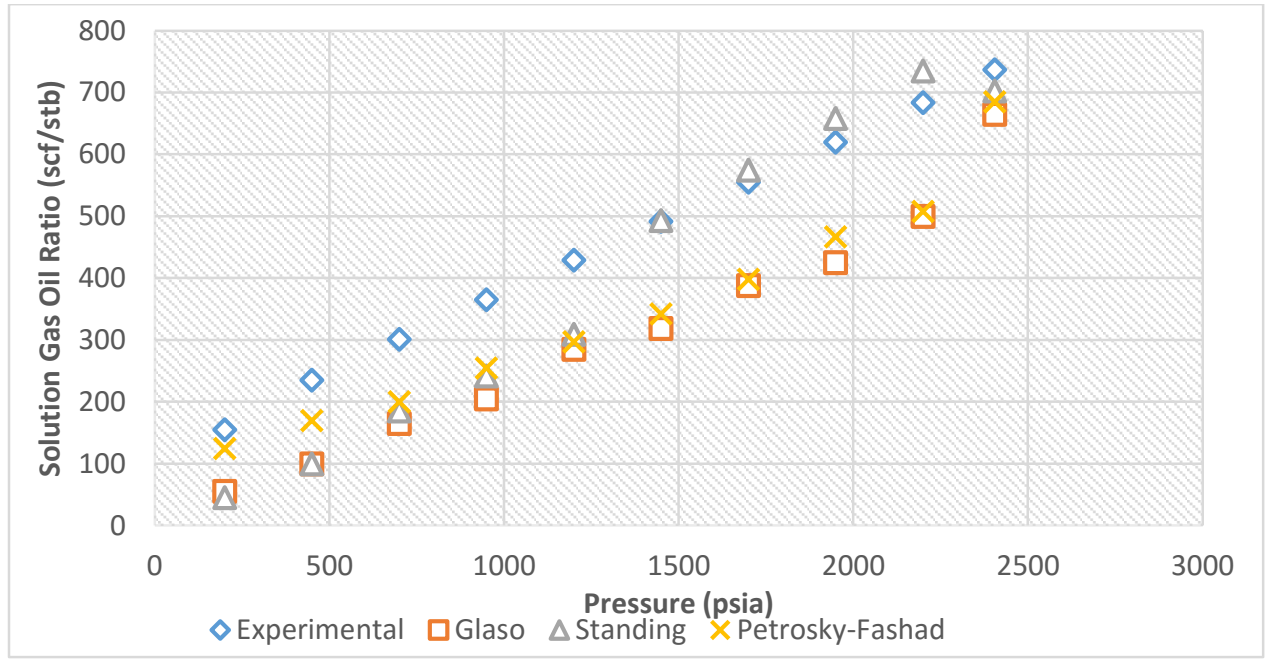

Figure 2: Result of gas solubility from correlations and experimental data

\section{ESTIMATED RESULT FROM PSO ALGORITHM}

The result of Standing's correlation gave the largest disparity than the other two correlations, hence, it was optimized with the particle swamp optimization algorithm to achieve the objective of this study. The particle swamp optimization algorithm is an iterative process that cannot be done manually, thus, it was programmed in Microsoft Excel to get the global best value for the constant A, B and C respectively as shown in Figures A1, A2 and A3 in the appendix section.

Convergence criteria is a phenomenon of PSO in which all particles tend to converge to a single value as shown by Figures A1, A2 and A3 respectively where all three particles maintain a single value at the $216^{\text {th }}$ iteration 
number. These single values represent the optimum solution to the objective function as discussed above; the values of $x_{i}=\left(A_{i}, B_{i}, C_{i}\right)$ at the $216^{\text {th }}$ iterations are $x_{i}^{216}=(17.53468968,0.053651478,0.745392522)$ respectively. Hence, the new empirical correlation used in estimating the gas solubility derived from particle swam optimization (PSO) algorithm, an optimization of standing correlation is given by equation $1 \& 2$.

$$
R_{\text {si }} \text { optimized }=\gamma_{g}\left[\left(\frac{p}{17.53468968}+1.4\right) 10^{0.053651478 A P I-0.00091(T-460))}\right]^{0.745392522}
$$

Table 3 shows the estimated result obtained from the new correlation developed in this study.

Table 3: Gas solubility (scf/stb) result for this study

\begin{tabular}{llllll}
\hline Pressure (psig) & Experimental & Glaso & Standing & Petrosky and Fashad & (This study) \\
\hline 2405 & 737 & 665 & 703 & 685 & 724 \\
2200 & 684 & 500 & 735 & 508 & 678 \\
1950 & 620 & 425 & 658 & 467 & 620 \\
1700 & 555 & 388 & 575 & 398 & 560 \\
1450 & 492 & 319 & 493 & 342 & 498 \\
1200 & 429 & 285 & 309 & 297 & 434 \\
950 & 365 & 205 & 242 & 255 & 365 \\
700 & 301 & 165 & 185 & 200 & 294 \\
450 & 235 & 100 & 100 & 170 & 214 \\
200 & 155 & 55 & 45 & 125 & 122 \\
\hline
\end{tabular}

\section{RESULT OF CROSS PLOT}

To graphically illustrate the success of the existing correlations, a performance or cross plot was performed as shown in Figures 4-6, which is a plot of the estimated values versus the experimental values. A $45^{\circ}$ straight line was drawn on the cross plot on which the estimated value is equal to the experimental value. Fitting the straight line at $45^{\circ}$ clearly indicates that, the closer the plotted data points are to this line, the better the correlation. The result of Petrosky-Fashad, Glaso, and Standing correlations show a clear disparity from the experimented. 


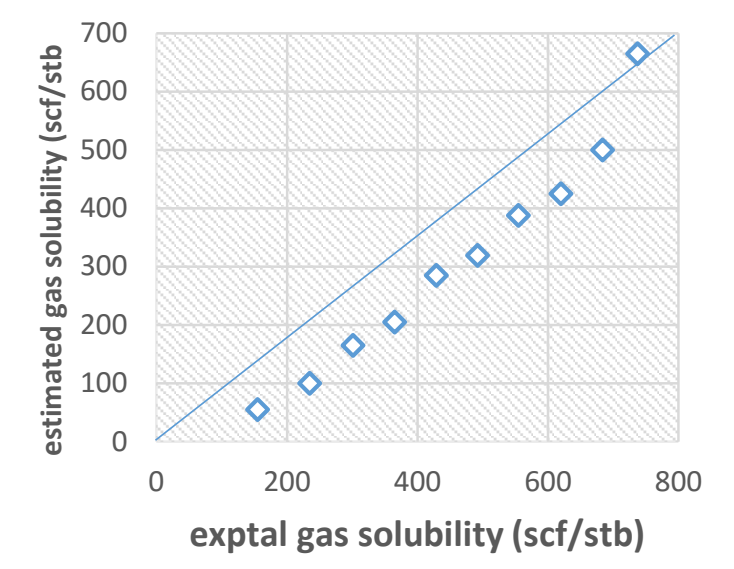

Figure 3: Cross plots for Gas Solubility using Standing Correlation

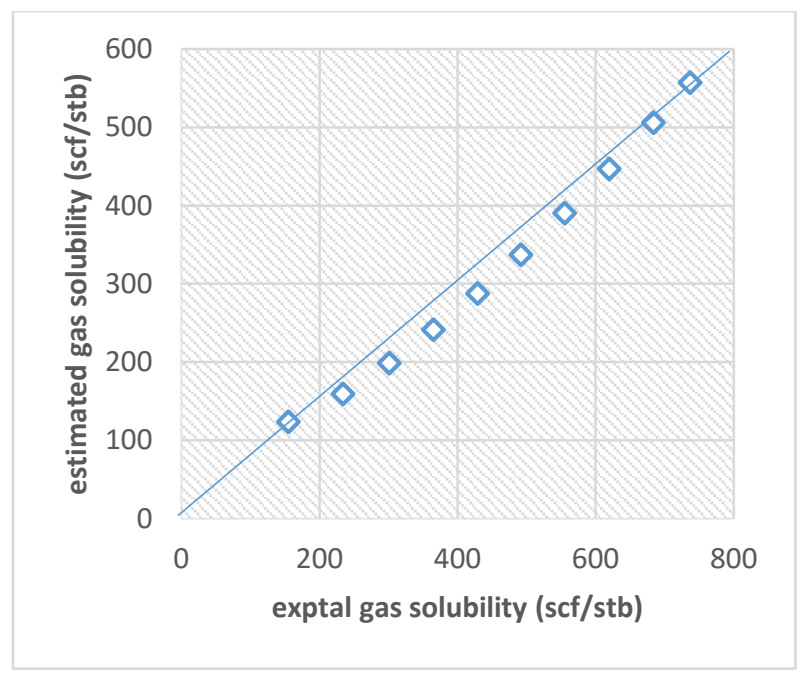

Figure 5: Cross plots for Gas Solubility using Petrosky and Farshad correlation

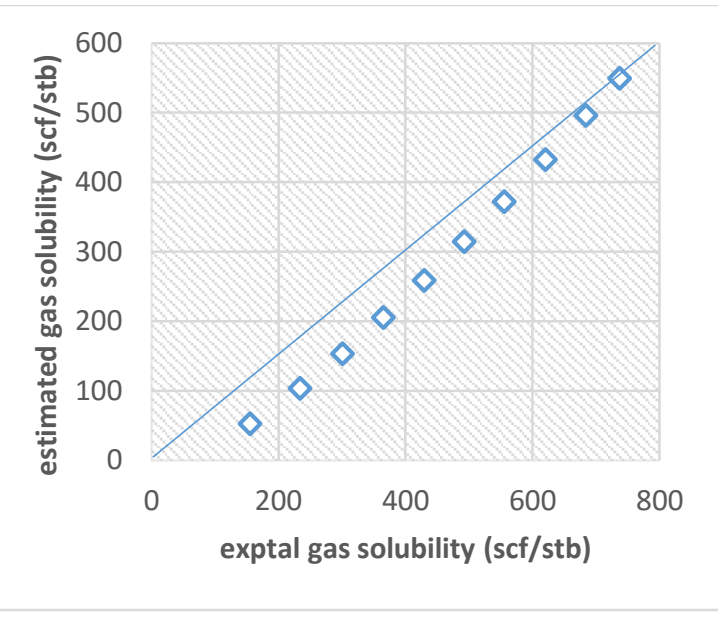

Figure 4: Cross plots for Gas Solubility using Glaso Correlation

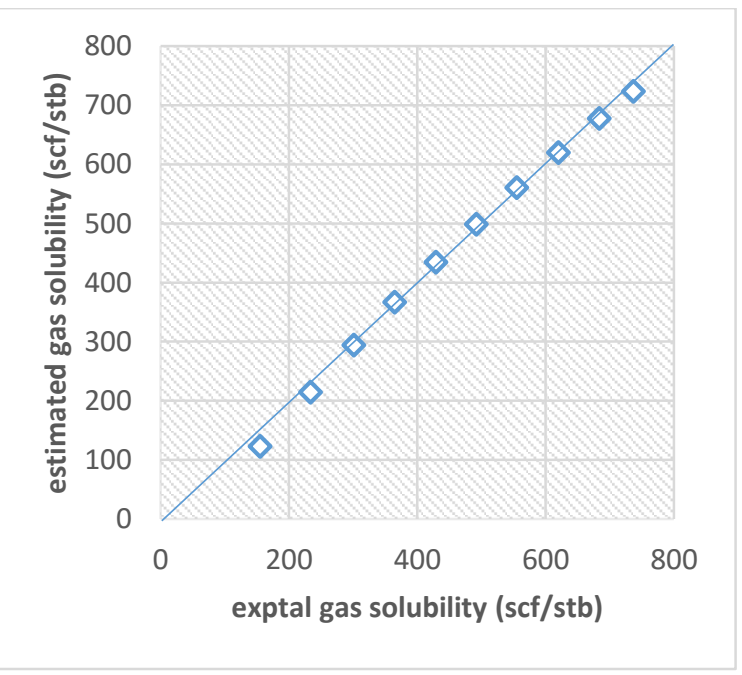

Figure 6: Cross plots for gas solubility for this study

\section{STATISTICAL ERROR ANALYSIS}

According to the Tables 4, it is clarified that the errors calculated by this study's correlation are lower than the other three correlations as shown in Figures 3-6 and newly developed correlation is most accurate for pressure below the bubble point pressure, yielding an average percent relative error of $3.34 \%$ and correlation coefficient of 0.998 which means that the sum of squares about regression is minimal i.e. the unexplained variation by regression and thus agree that the best correlation should have the least average percent relative error and highest correlation coefficient between zero and one. 
Table 4: Statistical analysis of correlations

\begin{tabular}{lllll}
\hline Statistical parameter & This study & $\begin{array}{l}\text { Standing } \\
\text { correlation }\end{array}$ & $\begin{array}{l}\text { Glaso } \\
\text { correlation }\end{array}$ & $\begin{array}{l}\text { Petrosky and Farshad } \\
\text { correlation }\end{array}$ \\
\hline $\begin{array}{l}\text { Average percent relative error } \\
(\%)\end{array}$ & 3.34 & 30.22 & 40.11 & 29.3 \\
Sum squared residual & 364985 & 566488 & 522387 & 373945 \\
Correlation coefficient & 0.998 & 0.9167 & 0.8097 & 0.8089 \\
\hline
\end{tabular}

\section{CONCLUSIONS}

Based on the results of this evaluations, the following remarks are worth mentioning:

- An empirical correlation for estimating the gas solubility at the bubble point pressure and below for black oils has been developed.

- The result obtained with the data from the differential liberation test, shows that the correlation developed in this study performs better than Standing's, Glaso's and Petrosky's correlations. Hence, engineers can rely on the newly developed correlation to an extent after the have validated it with their field data because it is stated in literatures that correlation performs better in the region it was developed.

- The statistical result indicates a lower value of average relative error and a better coefficient of correlation for this study than for Standing's, Glaso's and Petrosky's correlations at pressures below bubble point.

- The particle swarm optimization tool achieves a better accuracy by minimizing the objective function generated in this study. Above bubble point, solution gas oil ratio is the same with solution gas oil ratio at bubble point.

- Further work is recommended in developing a modification of Particle swarm optimization with faster convergence rate. 


\section{REFERENCES}

Al-Marhoun, M. A. 1988. PVT Correlations for Middle East Crude Oils. Journal of Petroleum Technology, 88 (05): 650-666. doi:10.2118/13718-PA

Glaso, O. (1980). Generalized Pressure-Volume Temperature Correlations. Journal of Petroleum Technology, 80(05): 785-95. doi:10.2118/8016-PA

Hilary, O. and Okotie, S. (2016). Improved Correlation for Predicting Stock Tank Gas-Oil Ratio in Niger Delta. Presented at the SPE Nigeria Annual International Conference and Exhibition, Lagos, Nigeria 4-6 $6^{\text {th }}$ August. SPE 184374. doi:10.2118/184374-MS

Ikiensikimama, S. S. and Egbe T. (2006). Improved PVT Screening Methodology. Technical Transactions on Software Engineering, 1, 59-67.

Ikiensikimama, S. S. (2008). The performance of Empirical PVT Correlations for Predicting Reservoir Fluid Properties for Some Niger Delta Crude. Ph.D Dissertation, University of Lagos, Lagos - Nigeria.

Kartoatmodjo, T. and Schmidt, Z. 1994. Large data bank improves crude physical property correlations. Oil and Gas Journal. pp. 51-51.

Okotie, S., Ofesi, S., Ikporo, B. (2017). PVT Analysis Reports of Akpet GT9 and GT12 Reservoirs. American Journal of Management Science and Engineering. 2(5): 132-144. doi: 10.11648/j.ajmse.20170205.17

Oloruntoba, F. M. and Onyekonwu, M. O. (2016). Empirical prediction of bubble point pressure and solution gas oil ratio for Niger Delta. International Journal of Scientific \& Engineering Research, 7(6): 520-529.

Petrosky, G. E. abd Farshad, F. F. (1993, January 1). Pressure-Volume-Temperature Correlations for Gulf of Mexico Crude Oils. Society of Petroleum Engineers. doi:10.2118/26644-MS

Standing, M. B. (1947). A pressure volume temperature correlation for mixture of California oils and gases in Drilling \& Production. Practice. American Petroleum Institute, 275-87. 


\section{APPENDIX}

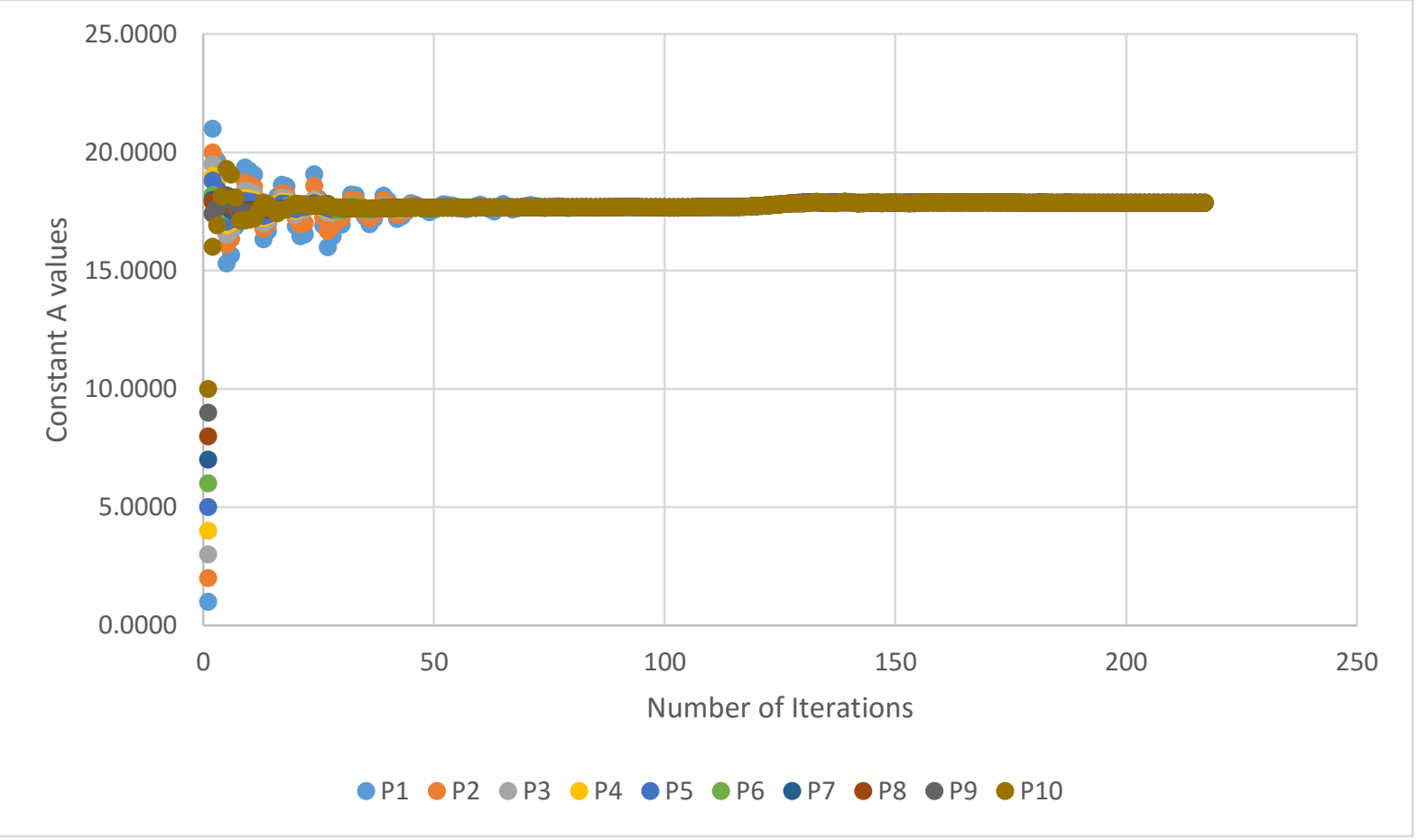

Figure A1: Constant A values from PSO iteration

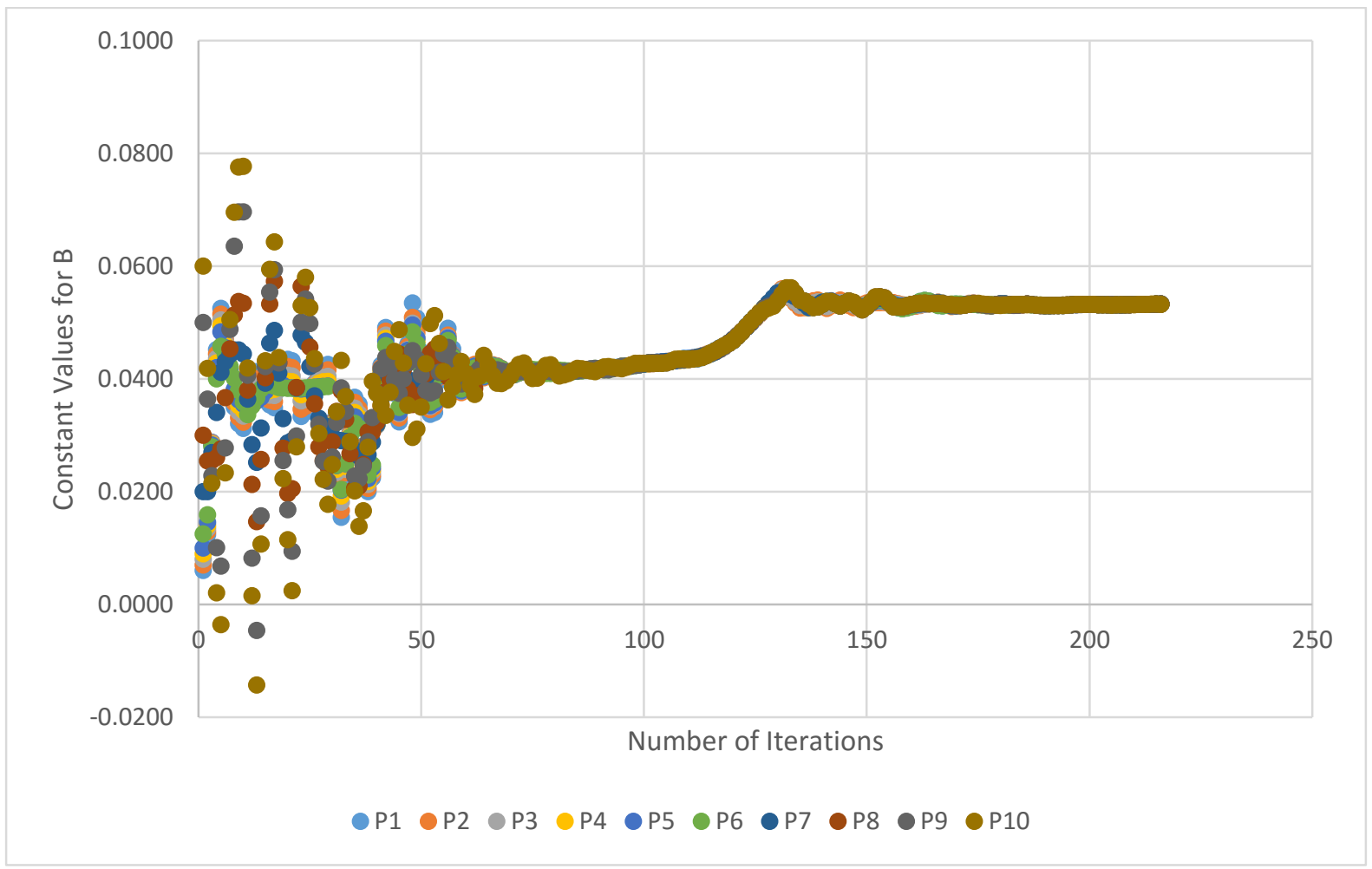

Figure A2: Constant B values from PSO iteration 


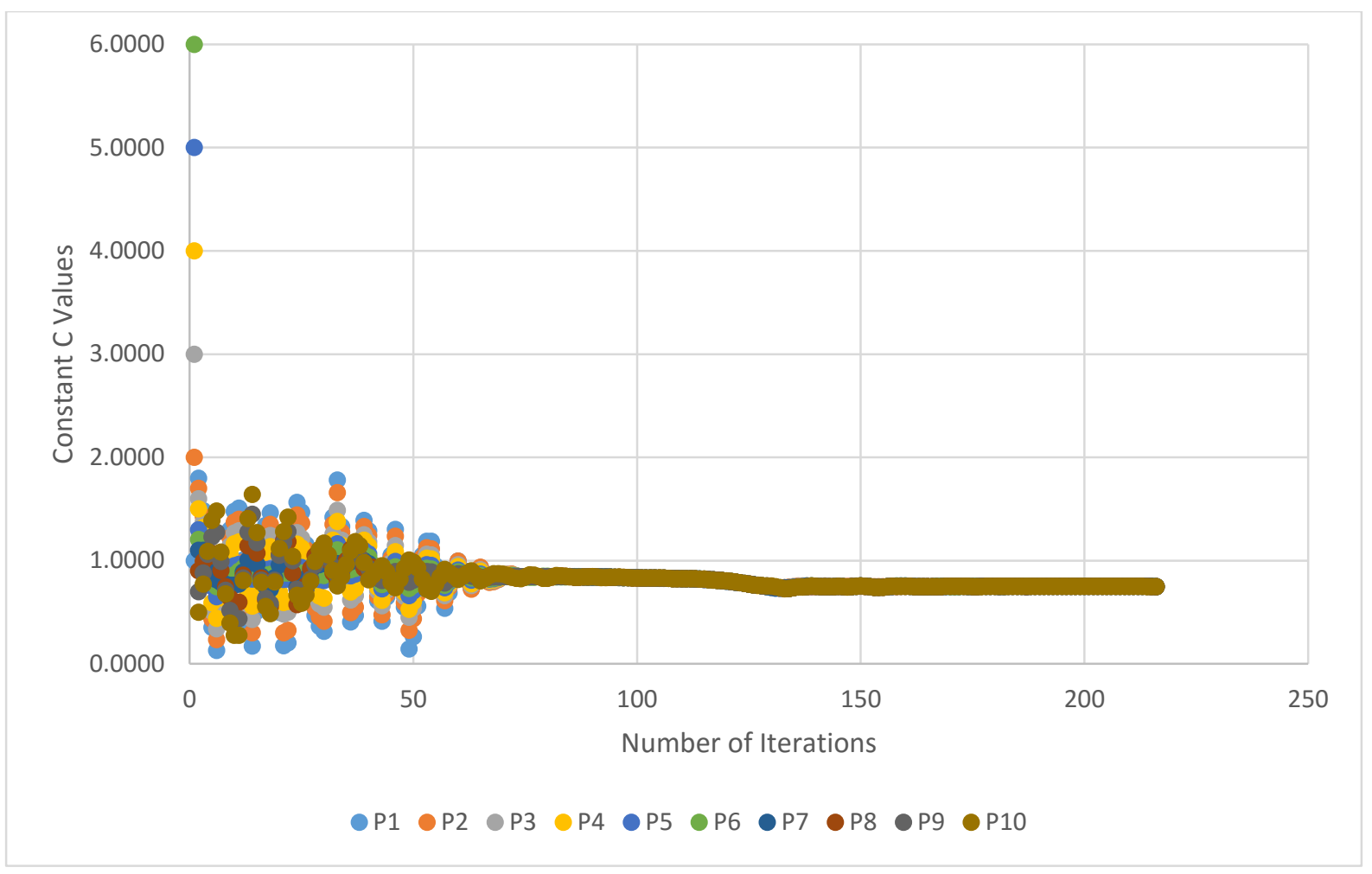

Figure A3: Constant $\mathrm{C}$ values from PSO iteration 